\title{
Female northern grass lizards judge mates by body shape to reinforce local adaptation
}

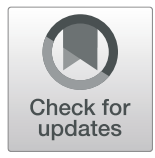

\author{
Kun Guo, Chen Chen, Xiao-Fang Liang, Yan-Fu Qu and Xiang Ji 'D
}

\begin{abstract}
Background: Identifying the factors that contribute to divergence among populations in mate preferences is important for understanding of the manner in which premating reproductive isolation might arise and how this isolation may in turn contribute to the evolutionary process of population divergence. Here, we offered female northern grass lizards (Takydromus septentrionalis) a choice of males between their own population and another four populations to test whether the preferences that females display in the mating trials correlate with phenotypic adaptation to local environments, or to the neutral genetic distance measured by divergence of mitochondrial DNA sequence loci.

Results: Females showed a strong preference for native over foreign males. Females that mated with native versus foreign males did not differ from each other in mating latency, or copulation duration. From results of the structural equation modelling we knew that: 1) geographical distance directly contributed to genetic differentiation and environmental dissimilarity; 2) genetic differentiation and environmental dissimilarity indirectly contributed to female mate preference, largely through their effects on morphological divergence; and 3) females judged mates by body shape (appearance) and discriminated more strongly against morphologically less familiar allopatric males.

Conclusions: Local adaptation rather than neutral genetic distance influences female mate preference in $T$. septentrionalis. The tendency to avoid mating with foreign males may indicate that, in T. septentrionalis, local adaptations are more valuable than genetic novelties. Our results highlight the importance of comprehensive studies integrating ecological, molecular and behavioral approaches to understand population divergence in female mate preferences as the consequence of local adaptations.
\end{abstract}

Keywords: Geographical distance, Genetic differentiation, Local adaptation, Mate preference, Morphology, Structural equation model

\section{Background}

Geographically separated populations accumulate genetic and phenotypic differences through genetic drift and/or adaptation to local environmental conditions [1]. The roles of local adaptation and consequent divergent selection between environments on the evolution of mate preferences are widely recognized in the literature and have been documented in diverse taxonomic groups

\footnotetext{
* Correspondence: jixiang@njnu.edu.cn

Jiangsu Key Laboratory for Biodiversity and Biotechnology, College of Life Sciences, Nanjing Normal University, Nanjing 210023, Jiangsu, China
}

such as snails [2], crustaceans [3, 4], insects [5-8], fish [9-14], amphibians [1, 15-17], reptiles [18], birds [19, 20] and mammals [21, 22]. From previous studies on mate preference in females, which account for the vast majority of published papers focusing on this issue, we know the following. First, mate preferences are often evaluated with respect to behaviors associated with their intentions of rejecting and/or accepting males rather than actual copulations with males [18]. Second, local adaptations are more valuable than genetic novelties in most of the species studied thus far, as revealed by the fact that females of these species prefer to mate with native (local) over foreign 
males [2]. To our knowledge, the Trinidadian guppy Poecilla reticulata [9], the sailfin molly Poecilia latipinna [13], the striped mouse Rhabdomys pumilio [22], the Pacific blue-eye Pseudomugil signifer [14] and the rainwater killifish Lucania parva [11] represent the exceptions of species where female mate preference for native males is strong in some populations but not in others, or asymmetric in different populations. Third, comprehensive studies integrating molecular, ecological, phenotypic and behavioral approaches to show changes in mate preference correlated with local adaptation are rare. To our knowledge, such studies have been performed only in P. signifer [14], the Allegheny mountain salamander Desmognathus ochrophaeus [17] and the fire salamander Salamandra salamandra [15] where female mate preferences depend either on local adaptation rather than neutral genetic distance ( $S$. salamandra), or on how genetically and geographically separated populations are from one another (P. signifer and D. ochrophaeus).

Divergence among populations in mate preferences is a crucial step of population differentiation and potential speciation because it may lead to premating reproductive isolation [23, 24]. Identifying the factors that contribute to such a divergence is therefore important for understanding of the manner in which premating reproductive isolation might arise and how this isolation may in turn contribute to the evolutionary process of population divergence and incipient speciation [25]. However, as the roles of individual factors in mate assessment by males or females are not mutually exclusive, disentangling their effects on mate preferences is difficult. Fortunately, the recent progress in statistical methods for spatial data analysis and the increasing availability of high-resolution geographical and environmental data layers make it possible to evaluate the relative contributions of the factors to population divergence in mate preferences.

The northern grass lizard (Takydromus septentrionalis) is a multiple-clutched oviparous lacertid lizard endemic to China and has a distributional range covering the central and southeastern parts of the country [26]. The lizard consists of three divergent lineages, with isolation by distance known to be the main cause of genetic divergence [27]. Proximate factors are less important determinants of spatio-temporal variation in life-history traits (e.g., size at maturation, adult size, clutch size, clutch frequency and egg size) than are genetic influences [28-31]. Adults can have up to three distinct color morphs within a population: morph 1 is shared by both sexes, with a yellowish-white longitudinal stripe between brown dorsal and green lateral surfaces; morph 2 is a typical male coloration, with morph 1 decorated with numerous black speckles on the lateral surface; morph 3 is a typical female coloration, with brown dorsal and green lateral surfaces connected directly (Additional file 1).
Although small adults do mate less frequently than large ones, the lizard does not show size-assortative mating [32]. Males are the less choosy sex, as revealed by three lines of evidence. First, they can be easily induced to mate at extreme phylogenetic distances, either with conspecific females from other populations, or even with heterospecific (but congeneric) females (e.g., T. sexlineatus) (Fig. 1a), which is an extreme example of outcrossing. Second, males are often found to mate with one another in a manner adopted by heterosexual mating partners (Fig. 1b). Third, female receptivity rather than male sexual coercion (and thus forced insemination) has a direct role in determining mating success, and females are more receptive to mate within $2 \mathrm{~d}$ post-laying and much less so thereafter [32]. Here, we describe a study offering each post-laying female T. septentrionalis 10 males, two from each of five geographically separated populations (see below for details), to test whether the species also shows a female mate preference for local males and, if so, whether the preferences that females display in the mating trials correlate with phenotypic adaptation to local environments, or to the neutral genetic distance measured by divergence of mitochondrial DNA sequence loci.

\section{Materials and methods}

\section{Animal collection and maintenance}

We collected adult T. septentrionalis in early April 2015 from five populations that are between 50 and $1340 \mathrm{~km}$ apart: three mainland populations in Chang'an (CA: $\left.34^{\circ} 01^{\prime} \mathrm{N}, 108^{\circ} 58^{\prime} \mathrm{E}\right)$, Chuzhou (CZ: $\left.32^{\circ} 11^{\prime} \mathrm{N}, 118^{\circ} 11^{\prime} \mathrm{E}\right)$ and Lishui (LS: $28^{\circ} 26^{\prime} \mathrm{N}, 119^{\circ} 55^{\prime} \mathrm{E}$ ); two island populations in Liuheng (LH: $\left.29^{\circ} 43^{\prime} \mathrm{N}, 122^{\circ} 08^{\prime} \mathrm{E}\right)$ and Xiushan (XS: $30^{\circ} 10^{\prime} \mathrm{N}, 122^{\circ} 10^{\prime} \mathrm{E}$ ), Zhoushan Islands (Fig. 2). Healthy lizards without visible ectoparasites were brought to our laboratory within a week of capture. A total of 150 males of morph 1 shared by both sexes, 30 from each of five populations, and 100 LS females yet to lay their first clutch were used in this study. Each male was painted with a unique Arabic number on the belly for identification. Measurements taken for each lizard included snout-vent length (SVL), abdomen (or axillogroin) length (AL, between the inserting points of the fore- and hind-limbs), head length (HL, from the snout to the anterior edge of the external auditory meatus) and head width (HW, taken at the posterior end of the mandible). Males from the five populations differed morphologically (both body size and body shape): the mean SVL was greatest in the CA population and smallest in the LS, LH and XS populations; the SVL-adjusted mean AL was greater in the $\mathrm{CZ}$ and $\mathrm{CA}$ populations than in the LS, LH and XS populations; the SVL-adjusted HL was greatest in the LS population and smallest in the CA population; the SVL-adjusted mean HW was greater in 


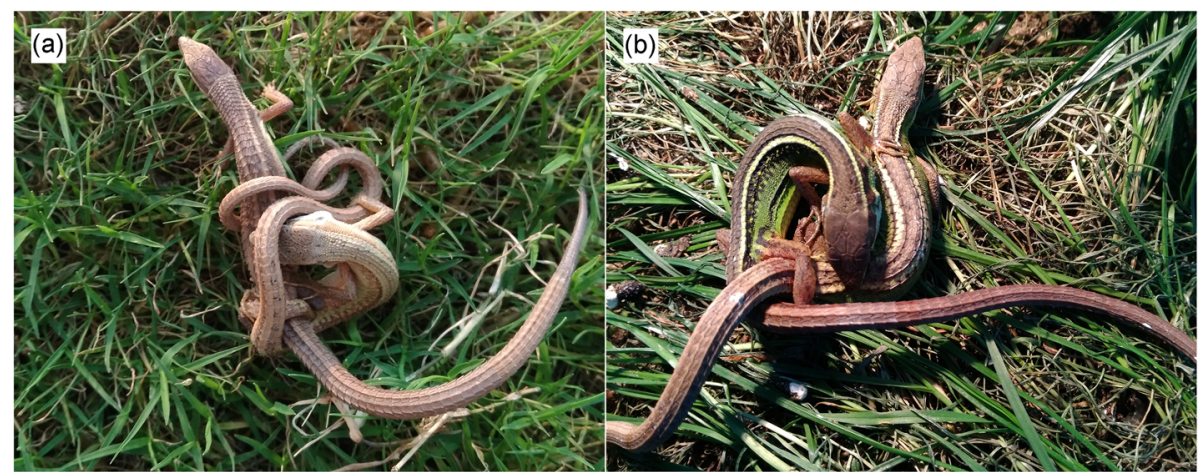

Fig. 1 The body posture of heterospecific $\mathbf{a}$, between male T. septentrionalis and female T. sexlineatus) and conspecific homosexual $\mathbf{b}$, between males of $T$. septentrionalis) mating partners

the LS and LH populations than in the XS, CZ and CA populations (Additional file 2).

Ten males (two randomly chosen from each of five populations) or 10 females from the LS population were housed in one $900 \times 600 \times 400$ (length $\times$ width $\times$ height) $\mathrm{mm}$ cage with a soil substrate $(\sim 50 \mathrm{~mm}$ depth) covered with grass and pieces of clay tile. All cages were placed in a room inside which temperatures varied from 20 to $28^{\circ} \mathrm{C}$. Thermoregulatory opportunities were provided between $07: 00-19: 00 \mathrm{~h}$ by a $60 \mathrm{~W}$ full-spectrum lamp at one end of each cage to create a thermal gradient from room temperature to $\sim 50{ }^{\circ} \mathrm{C}$ during the photophase. Mealworms (Tenebrio molitor), house crickets (Achetus domesticus) and water enriched with vitamins and minerals were provided daily. All lizards used in this study were released to the sites where they were originally captured in early August, soon after the breeding season.

\section{Mate choice trials}

Only females that had just laid the first clutch were used to test their mate preference for native versus foreign males. We randomly moved a post-laying female into one all-male cage. Mating often took place in $90 \mathrm{~min}$, and any female that did not mate with a male in $2 \mathrm{~h}$ was randomly moved into another all-male cage. We recorded mating latency (time from putting a female in an all-male cage to the beginning of copulation) and copulation duration (time from the beginning to the end of copulation) for each mated pair. Of the 100 females tested, 99 successfully mated in $2 \mathrm{~d}$ post-laying.

\section{Geographical, genetic, environmental and morphological differences}

We calculated geographic distance for each pair of populations based on their latitude and longitude data using

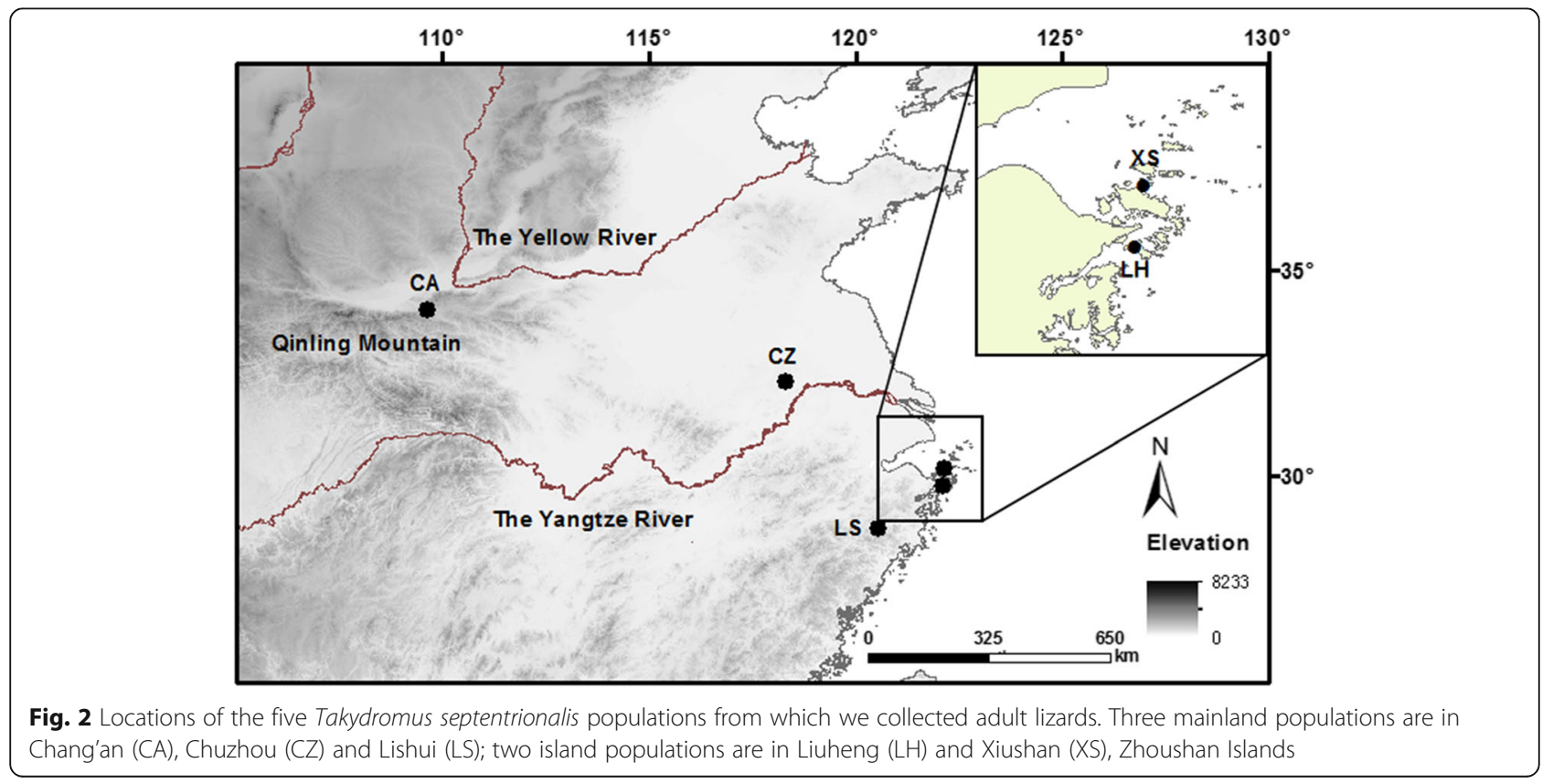


Geographic Distance Matrix Generator 1.2.3 [33]. We quantified genetic divergence $(F \mathrm{st})$ for each pair of populations based on a fragment of mitochondrial DNA that was 1143 base pairs long [27]. We performed a principal components analysis (PCA) for the five populations to resolve two components (eigenvalues $\geq 1$ ) from 22 environmental (three geographical and 19 climatic) variables (https://www.worldclim.org [34]), explaining 92\% of the variation in the original data (Additional file 3). We performed a PCA for 150 adult males from the five populations to resolve two components (eigenvalues $\geq 1$ ) from three SVL-adjusted body-shape variables, explaining $91 \%$ of the variation in the original data (Additional file 4). We calculated environmental and morphological divergence between each pair of populations as the difference in their mean PC1 scores.

\section{Statistical analyses}

All statistical analyses were performed using Statistica 8.0 (StatSoft Inc., Tulsa, OK, USA). We used a $G$ test to examine whether female mate preference was populationdependent. We used PCA scores to show environmental and morphological differences between populations. We used nonlinear estimation to show the frequency of matings in relation to geographic distance, genetic differentiation, environmental dissimilarity and morphological difference. We used one-way ANOVA or ANCOVA with SVL as the covariate to examine whether mating latency, mating duration and morphological traits measured differed among the five populations. We used mixed model ANOVA with population origin as the fixed factor and cage ID as the random factor to examine whether the distribution of male morphologies (PC1 scores) available to individual females in mate choice trials matched the overall distribution of male morphologies from the five populations. A Tukey's post-hoc test was performed when necessary to find means that were significantly different from each other.

We performed statistical analyses for structural equation modelling (SEM) in AMOS 21.0 [35] to quantify the relative contributions of geographical distance, genetic differentiation, environmental dissimilarity and morphological difference to female mate preference, showing the paths and framework among the five variables. We constructed a priori models and tested the optimized one with a method unweighted least squares in SEM [36]. We used z-scores to standardize data, thereby controlling for the influence of dimensional differences among variables.

\section{Results}

Population origin $\left(F_{4,56}=37.52, P<0.001\right)$ but not cage ID $\left(F_{14,56}=1.39, P=0.485\right)$ or the population $\times$ cage interaction $\left(F_{56,75}=0.60, P=0.975\right)$ was a significant source of morphological variation for males in 15 all- male cages. The lack of a significant cage effect suggested that the distributions of morphological traits in individual all-male cages did not deviate from the overall distribution of male morphologies from the five populations. Table 1 and Fig. 3 show the results of the female preference tests for males from native versus foreign populations. Females showed a strong preference for native over foreign males $(G=79.86, d f=4, P<0.001)$. Of the $99 \mathrm{LS}$ females mating in $2 \mathrm{~d}$ post-laying, 52 mated with males from their own population, 25 with XS males, 12 with LH males, 9 with CZ males, and 1 with a CA male. Females that mated with native versus foreign males did not differ from each other in mating latency $\left(F_{3,94}=0.60, P=0.620\right)$, or copulation duration $\left(F_{3,94}=\right.$ $2.24, P=0.089)$. The frequency of matings between females and males from different populations generally decreased at an ever-decreasing rate as geographical distance (Fig. 3a), genetic differentiation (Fig. 3b), or the male's mean environmental PC1 score (Fig. 3c) increased, but at almost the same rate as the male's mean morphological PC1 score increased (Fig. 3d).

All model-fit indices [CMIN $=0.010(d f=15, P>0.05)$, $\mathrm{RMR}=0.003, \quad \mathrm{GFI}=0.997, \quad \mathrm{AGFI}=0.992, \quad \mathrm{NFI}=0.995$, $\mathrm{RFI}=0.991]$ supported that the model and framework we selected were optimized (Fig. 4). From the results of SEM we knew the following. First, geographical distance directly contributed to genetic differentiation and environmental dissimilarity. Second, genetic differentiation directly contributed to morphological difference, and so did environmental dissimilarity although its role in shaping morphology was comparatively less substantive. Third, morphological difference directly contributed to female mate preference. Fourth, genetic differentiation and environmental dissimilarity indirectly contributed to female mate preference, largely through their effects on morphological divergence. Fifth, genetic and morphological divergence had greater total effects on female mate preference than did geographical distance and environmental dissimilarity (Additional file 5).

\section{Discussion}

Males collected from the five allopatric populations differed morphologically and genetically. More specifically, they differed not only in body size but also in body shape (appearance) as revealed by the fact that SVLspecific mean values for AL, HL and HW differed among the five populations (Additional file 3), and their neutral genetic divergence generally increased as geographical distance increased [27]. In the scenario of maximizing genetic novelties, we would have expected female northern grass lizards to mate more frequently with foreign males, but this did not happen, even though such a preference could benefit females in leading to the production of genetically more different offspring. 
Table 1 Descriptive statistics, expressed as mean \pm SE and range, for female SVL, male SVL, mating latency and copulation duration. All females were from the Lishui population, and males from five geographically distinct populations

\begin{tabular}{llllll}
\hline Male populations & $n$ & Female SVL $(\mathrm{mm})$ & Male SVL $(\mathrm{mm})$ & Mating latency (min) & Copulation duration (min) \\
\hline Lishui (LS) & 52 & $65.4 \pm 0.4(60.0-73.7)$ & $65.9 \pm 0.3(60.6-69.2)$ & $23.6 \pm 2.4(1-90)$ & $153.0 \pm 7.0(34-325)$ \\
Xiushan (XS) & 25 & $66.4 \pm 0.7(60.0-71.9)$ & $65.2 \pm 0.3(61.7-69.3)$ & $19.0 \pm 2.2(6-55)$ & $168.8 \pm 9.5(41-269)$ \\
Liuheng (LH) & 12 & $64.6 \pm 0.8(60.4-68.5)$ & $66.9 \pm 0.7(63.1-72.7)$ & $15.0 \pm 1.7(9-25)$ & $187.5 \pm 16.5(94-320)$ \\
Chuzhou (CZ) & 9 & $64.3 \pm 0.7(61.0-68.3)$ & $66.4 \pm 1.6(60.2-70.1)$ & $17.0 \pm 2.3(6-26)$ & $129.1 \pm 13.3(76-210)$ \\
Chang'an (CA) & 1 & 61.1 & 79.8 & 30 & 140 \\
\hline
\end{tabular}

Instead, when offering LS females the choice between males from their own population and other four populations, we found that they were capable of distinguishing between native and foreign males and strongly discriminated against foreign males to facilitate population divergence or local adaptation. Like D. ochrophaeus [17] and $P$. signifer [14], the degree of female discrimination against foreign males in $T$. septentrionalis depends on how geographically and genetically separated populations are from one another (Table 1; Figs. 3a, b). This finding raises the question of how females distinguish between native males and those from other populations separated by various distances to their own. In order to answer this question, we discuss below the implications of our results for the roles of individual factors in mate assessment by female northern grass lizards and their relative contributions to population divergence in female mate preferences.

Our data showed a strong concordance between the extent of geographical isolation among the five populations
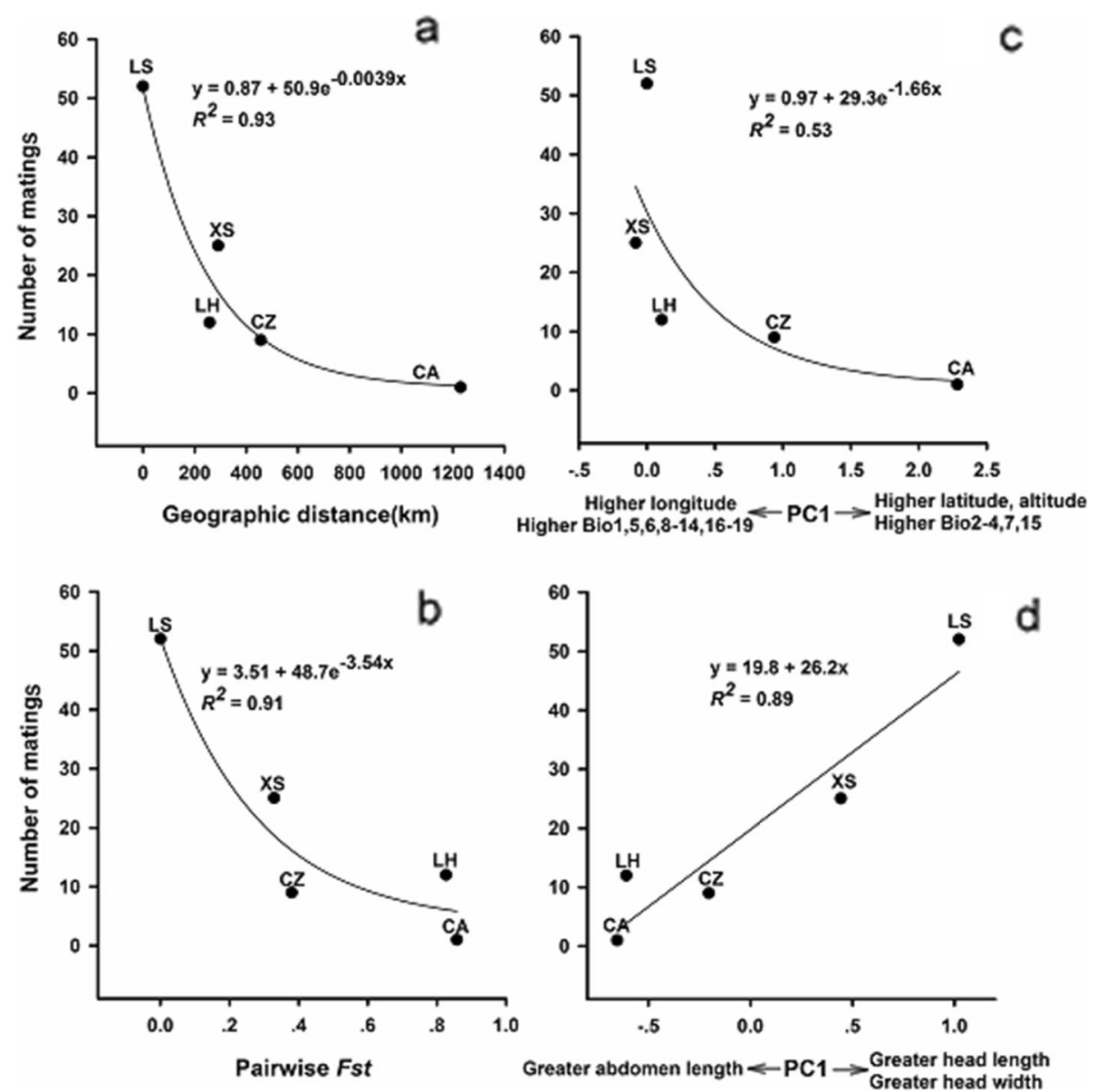

Fig. 3 Frequency of matings in relation to geographical distance a, pairwise Fst (a measure of genetic differentiation between populations, $\mathbf{b}$, environmental dissimilarity $\mathbf{c}$ and morphological difference $\mathbf{d}$. Regression equations and coefficients are given in the figure. See Fig. 2 for abbreviations for sampling locations 


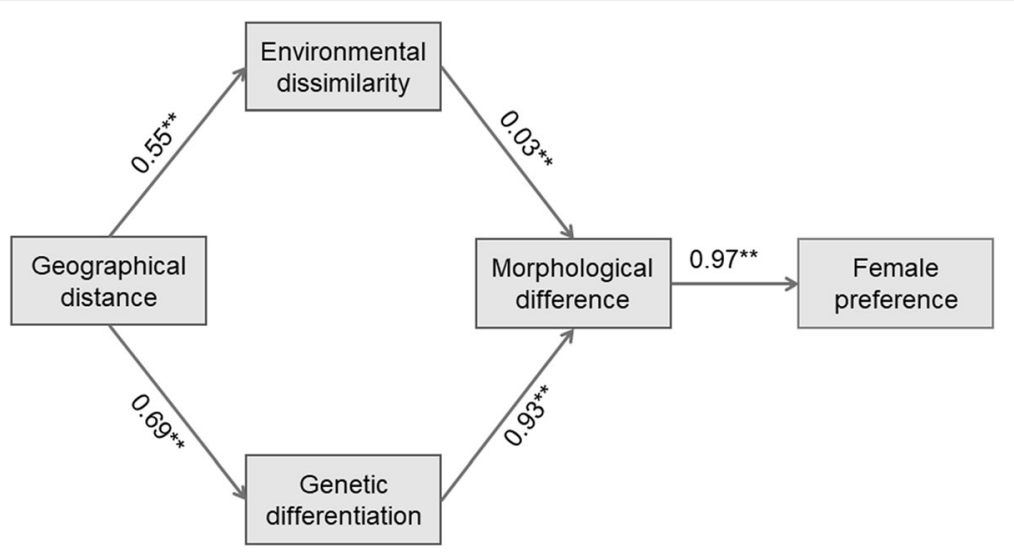

Fig. 4 The most supported structural equation model for the roles of geographical distance, genetic differentiation, environmental dissimilarity and morphological difference in mate assessment by female T. septentrionalis. Numbers given in the figure represent the standard direct effects, and the symbol ** represents $p<0.01$

and the degree of genetic differentiation (Fig. 4), supporting a widely accepted idea that more distant allopatry should reflect reduced rates of contemporary gene flow and thus increased genetic differentiation [9, 14, 17]. More distantly allopatric populations of T. septentrionalis have undergone greater divergence in female mate preferences associated with longer periods of genetic isolation [27]. This was evidenced by the ability of LS females to discriminate more strongly against males from populations geographically and genetically more distant to their own (Fig. 2b). However, our SEM analysis shows that genetic differentiation is not the direct determinant of population divergence in female mate preferences in T. septentrionalis. Instead, genetic differentiation influences female mate preference largely through its influence on morphological divergence (Fig. 4).

Like other lizards of diverse taxa including gekkonid [37], lacertid [38, 39], phrynosomatid [40] and scincid [41] species, morphological differences in T. septentrionalis are coupled with environmental differentiation [42], which is strongly concordant with geographical distance between populations (Fig. 4). Our morphometric analysis shows that male $T$. septentrionalis from genetically and geographically more proximate populations are more similar in appearance (Fig. 2d). Our SEM analysis further shows that male morphological divergence among populations reflects the combined effect of environmental and genetic differences and is of primary importance for population divergence in female mate preferences (Fig. 4). It worth noting, however, that a male's individual morphological traits such as body size and head size do not seem to influence mate assessment by female $T$. septentrionalis, as revealed by the following lines of evidence.
Like most lizards, the body posture (male grasps one side of female's body with teeth, and then male-female cloacal regions come into contact) of mating partners [including heterospecific [(between T. septentrionalis (male) and T. sexlineatus (female); Fig. 1a] and conspecific homosexual (between two males of $T$. septentrionalis; Fig. 1b) mating partners] in T. septentrionalis was primarily determined by the male's posture, remained nearly unchanged throughout the mating process and could not be achieved without relying on the male's bite force (Fig. 1). Bite forces are greater in lizards with larger heads $[43,44]$, and it is generalizable to lizards including $T$. septentrionalis that head size positively correlates with body size [45]. Thus, if any mating-related behavior (male sexual coercion, female receptivity, female proceptivity, or mate quality assessment by females) were associated with the body size, head size and thus bite force of males, mating latency and/or copulation duration would have been expected to differ among females mating with males from different populations (Additional file 2). Nevertheless, such differences were not observed in this study (Table 1), thus allowing us to conclude that female $T$. septentrionalis use the male's overall body appearance rather than individual morphological traits as cues or signals to recognize and mate assortatively according to their own habitat or population. This conclusion is consistent with that drawn for P. signifer where females prefer to mate with males from the native or nearby population also because of morphological and genetic similarities between closely related populations $[14,46]$. Mating with morphologically similar or familiar males could be a way of reinforcing local adaptation to diverse environmental conditions, avoiding homogenizing differences between allopatric populations and 
optimizing the local genotype of the offspring [15, 20, 47]. This is especially true for philopatric species such as T. septentrionalis [48], or for species such as most widespread Takydrumus lizards that occupy heterogeneous ranges, where offspring are likely to breed in the same habitat as their parents $[20,38,49,50]$.

\section{Conclusions}

In this study, we offered female T. septentrionalis from one population a choice of males from their own population and another four populations to test whether the preferences that females display in the mate choice trials correlate with phenotypic adaptation to local environments, or to the neutral genetic distance measured by divergence of mitochondrial DNA sequence loci. Our results show that female preference for males from their own population can be interpreted as population dependent assortative mating and generally support the hypothesis that local adaptation rather than neutral genetic distance influences female mate preference in T. septentrionalis. Female northern grass lizards judge native versus foreign mates by appearance. Our results highlight the importance of comprehensive studies integrating ecological, molecular and experimental behavior approaches to understand population divergence in mate preferences as a consequence of local adaptations, which can be a first and crucial step during the process of speciation. Future work could usefully investigate other visual signals and chemical signals to determine whether factors other than body shape may also contribute the decision process of $T$. septentrionalis. It has been found that Takydromus lizards among species having the visual [51] and chemical [52-55] communication systems and abilities to signal with conspecifics and alter their behaviour.

\section{Supplementary information}

Supplementary information accompanies this paper at https://doi.org/10. 1186/s12983-020-00367-9.

Additional file 1: Figure S1. Photos showing the three distinct color morphs. Morph 1 is shared by both females (a1) and males (a2), morph 2 is a typical male coloration (b), and morph 3 is a typical female coloration (c). Red, white and black colors on the head are not natural but temporary marks

Additional file 2: Figure S2. Descriptive statistics, expressed as mean (for SVL) or SVL-specific mean (for $\mathrm{AL}, \mathrm{HL}$ and $\mathrm{HW}$ ) values $+\mathrm{SE}$, for adult males collected from the Lishui (LS), Liuheng (LH), Xiushan (XS), Chuzhou (CZ) and Chang'an (CA) populations. Mean or SVL-specific mean values with different letters differed significantly (Tukey's post hoc test, $a=0.05$ ). All units are in $\mathrm{mm}$.

Additional file 3: Table S1. Loading of the first two axes of a principal component analysis on 22 geographical and climatic variables. Variables with the main contribution to each factor are in bold face font.

Additional file 4: Table S2. Loading of the first two axes of a principal component analysis on three size-adjusted morphological parameters, on which size effects were removed by using residuals from the regressions on snout-vent length. Variables with the main contribution to each factor are in bold face font

Additional file 5: Table S3. Results of the structural equation modeling for the relative contributions of four factors to female mate preference.

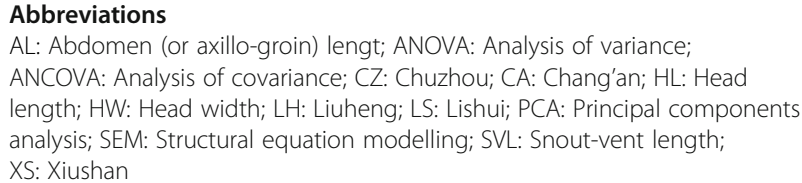

AL: Abdomen (or axillo-groin) lengt; ANOVA: Analysis of variance; ANCOVA: Analysis of covariance; CZ: Chuzhou; CA: Chang'an; HL: Head length; HW: Head width; LH: Liuheng; LS: Lishui; PCA: Principal components analysis; SEM: Structural equation modelling; SVL: Snout-vent length;

XS: Xiushan

\section{Acknowledgments}

We are grateful to Zhi-Hua Lin, Yan-Yan Sun and Jing Yang for valuable help with the field work and experiments at various stages of this study, and Hong An and Ting Zhou for comments on the experimental designs. We also thank Yao Cai for assistance with the molecular laboratory work. The work was carried out in compliance with laws on animal welfare and research in China, and all the necessary permissions to collect lizards used in this study were approved by local Chinese authorities.

\section{Authors' contributions}

$X J$ and $K G$ conceived and designed the experiment. $X J$ supervised the study. $K G, C C, X F L$ and YFQ conducted the experiment and collected the data. KG, YFQ and XJ analyzed the data and wrote the paper, and all authors reviewed and approved the final manuscript.

\section{Funding}

Funding for this study was provided by the National Natural Science Foundation of China (31301878 and 31300339) to XJ. The funders had no role in study design, data collection and analysis, decision to publish, or preparation of the manuscript.

\section{Availability of data and materials}

All data generated or analyzed during this study are included in this published article and its supplementary information files (Additional files 1, 2, 3, 4 and 5).

Ethics approval and consent to participate

This study was carried out in accordance with the Guide for the Care and Use of Laboratory Animals of the National Institutes of Health and was approved by the Ethical and Animal Welfare Commission of Nanjing Normal University (IACUC-201425).

Consent for publication

Not applicable.

\section{Competing interests}

The authors declare that they have no competing interests.

Received: 27 May 2020 Accepted: 24 July 2020

Published online: 04 August 2020

\section{References}

1. Hoskin CJ, Higgie M, McDonald KR, Moritz C. Reinforcement drives rapid allopatric speciation. Nature. 2005;437:1353-6.

2. Rupp JC, Woolhouse MEJ. Impact of geographical origin on mating behaviour in two species of Biomphalaria (Planorbidae: Gastropoda). Anim Behav. 1999;58:1247-51.

3. Durand S, Beauché F, Richard FJ, Beltran-Bech S. How do females' genetic characteristics influence male mate preference in the terrestrial isopod Armadillidium vulgare? Ethology. 2015;121:1122-30.

4. Galipaud M, Gauthey Z, Turlin J, Bollache L, Lagrue C. Mate choice and male-male competition among morphologically cryptic but genetically divergent amphipod lineages. Behav Ecol Sociobiol. 2015;69:1907-16.

5. Bewick ER, Dyer KA. Reinforcement shapes clines in female mate discrimination in Drosophila subquinaria. Evolution. 2014;68:3082-94.

6. Dyer KA, White BE, Sztepanacz JL, Bewick ER, Rundle HD. Reproductive character displacement of epicuticular compounds and their contribution 
to mate choice in Drosophila subquinaria and Drosophila recens. Evolution. 2014;68:1163-75.

7. Nosil P, Crespi BJ, Sandoval CP. 2003. Reproductive isolation driven by the combined effects of ecological adaptation and reinforcement. Proc R Soc B. 2003;270:1911-8.

8. Porretta D, Urbanelli S. Evolution of premating reproductive isolation among conspecific populations of the sea rockpool beetle Ochthebius urbanelliae driven by reinforcing natural selection. Evolution. 2012;66:1284-95.

9. Endler JA, Houde AE. Geographic variation in female preferences for male traits in Poecilia reticulata. Evolution. 1995:49:456-68.

10. Houde $A E$, Hankes MA. Evolutionary mismatch of mating preferences and male colour patterns in guppies. Anim Behav. 1997;53:343-51.

11. Kozak GM, Roland G, Rankhorn C, Falater A, Berdan EL, Fuller RC. Behavioral isolation due to cascade reinforcement in Lucania killifish. Am Nat. 2015;185: 491-56.

12. Magurran AE, Paxton GM, Seghers BH, Shaw PW, Carvalho GR. Genetic divergence, female choice and male mating success in Trinidadian guppies. Behaviour. 1996;133:503-17.

13. Ptacek MB, Travis J. Mate choice in the sailfin molly, Poecilia iatipinna. Evolution. 1997;51:1217-31.

14. Wong BBM, Keogh JS, Jennions MD. Mate recognition in a freshwater fish: geographical distance, genetic differentiation, and variation in female preference for local over foreign males. J Evol Biol. 2004;17:701-8.

15. Caspers BA, Junge C, Weitere M, Steinfartz S. Habitat adaptation rather than genetic distance correlates with female preference in fire salamanders (Salamandra salamandra). Front Zool. 2009;6:13.

16. Herring K, Verrell PA. Sexual incompatabilities and geographical variation in mate recognition systems: tests in the salamander Desmognathus ochrophaeus. Anim Behav. 1996;52:279-87.

17. Tilley SG, Verrell PA, Arnold SJ. Correspondence between sexual isolation and allozyme differentiation: a test in the salamander Desmognathus ochrophaeus. Proc Natl Acad Sci U S A. 1990;87:2715-9.

18. Bastiaans E, Bastiaans MJ, Morinaga G, Gaytán JGC, Marshall JC, Bane B, Méndez de la Cruz F, Sinervo B. female preference for sympatric vs. allopatric male throat color morphs in the mesquite lizard (Sceloporus grammicus) species complex. PLoS One. 2014;9:e93197.

19. Danner JE, Danner RM, Bonier F, Martin PR, Small TW, Moore IT. Female, but not male, tropical sparrows respond more strongly to the local song dialect: implications for population divergence. Am Nat. 2011;178:53-63.

20. López-Rull I, Lifshitz N, Garcia CM, Graves JA, Torres R. Females of a polymorphic seabird dislike foreign-looking males. Anim Behav. 2016;113:31-8.

21. Pillay N. Female mate preference and reproductive isolation in populations of the striped mouse Rhabdomys pumilio. Behaviour. 2000;137:1431-41.

22. Pillay N, Willan $\mathrm{K}$, Meester J. Evidence of pre-mating reproductive isolation in two allopatric populations of the vlei rat (Otomys irroratus). Ethology. 1995;100:61-71.

23. Rundle HD, Chenoweth SF, Doughty P, Blows MW. Divergent selection and the evolution of signal traits and mating preferences. PLoS Biol. 2005;3:e368

24. Svensson El, Runemark A, Verzijden MN, Wellenreuther M. Sex differences in developmental plasticity and canalization shape population divergence in mate preferences. Proc R Soc B. 2014;281:20141636.

25. Schluter $D$. Evidence for ecological speciation and its alternative. Science. 2009:323:737-41

26. Liu MY. Takydromus Daudin 1802. In: Zhao EM, Zhao KT, Zhou KY, editors. Fauna Sinica, Reptilia (Squamata, Lacertilia), Vol 2. Beijing, China: Science Press; 1999. p. 257-269.

27. Cai Y, Yan J, Xu XF, Lin ZH, Ji X. Mitochondrial DNA phylogeography reveals a west-east division of the northern grass lizard (Takydromus septentrionalis) endemic to China. J Zool Syst Evol Res. 2012;50(2):137-44.

28. Du WG, Ji X, Zhang YP, Lin ZH, Xu XF. Geographic variation in offspring size of a widespread lizard (Takydromus septentrionalis): importance of maternal investment. Biol J Linn Soc. 2010;101:59-67.

29. Du WG, Ji X, Zhang YP, Xu XF, Shine R. Identifying sources of variation in reproductive and life history traits among five populations of a Chinese lizard (Takydromus septentrionalis, Lacertidae). Biol J Linn Soc. 2005;85:443-53.

30. Ji X, Diong $\mathrm{CH}$. Does follicle excision always result in enlargement of offspring size in lizards? J Comp Physiol B. 2006;176:521-5.

31. Ji X, Du WG, Lin ZH, Luo LG. Measuring temporal variation in reproductive output reveals optimal resource allocation to reproduction in the northern grass lizard, Takydromus septentrionalis. Biol J Linn Soc. 2007;91:315-24.
32. An H. Mate choice, temperature-induced phenotypic variation of hatchlings and thermal requirements in the northern grass lizard Takydromus septentrionalis. M.S. Thesis, Nanjing Normal University, Nanjing, China; 2008.

33. Ersts PJ. Geographic distance matrix generator (version 1.2.3). American Museum of Natural History, Center for Biodiversity and Conservation. See http://biodiversityinformatics.amnh.org/open_source/gdmg; 2013.

34. Hijmans RJ, Cameron SE, Parra JL, Jones PG, Jarvis A. Very high resolution interpolated climate surfaces for global land areas. Int J Climatol. 2005;25: 1965-78.

35. Arbuckle JL. Amos 7.0 user's guide. Chicago, IL: SPSS; 2006.

36. Graham JM, Guthrie AC, Thompson B. Consequences of not interpreting structure coefficients in published CFA research: a reminder. Struct Equ Model. 2003;10(1):142-53.

37. Zhang YP, Ping J, Hao SL, Zhou HB. Temporal and spatial variation in life history traits of the Japanese gecko, Gekko japonicus. Herpetol J. 2016;26:305-11.

38. Li H, Qu YF, Ding GH, Ji X. Life-history variation with respect to experienced thermal environments in the lizard, Eremias multiocellata (Lacertidae). Zool Sci. 2011;28:332-8.

39. Ma L, Liu P, Su S, Luo LG, Zhao WG, Ji X. Life-history consequences of local adaptation in lizards: Takydromus wolteri (Lacertidae) as a model organism. Biol J Linn Soc. 2019;127:88-99.

40. Ramírez-Bautista A, Stephenson BP, Muñoz CS, Cruz-Elizalde R, HerńandezSalinas U. Reproduction and sexual dimorphism in two populations of the polymorphic spiny lizard Sceloporus minor from Hidalgo, México. Acta Zool. 2014;95:397-408.

41. Lu HL, Lin ZH, Li H, Ji X. Geographic variation in hatchling size in an oviparous skink: effects of maternal investment and incubation thermal environment. Biol J Linn Soc. 2014;113:283-96.

42. Du WG, Ji X, Zhang YP. Inter-population variation in life-history traits of a Chinese lizard (Takydromus septentrionalis; Lacertidae). Herpetol J. 2006;16: 233-7.

43. Herrel A, Spithoven L, Van Damme R, De Vree F. Sexual dimorphism of head size in Gallotia galloti: testing the niche divergence hypothesis by functional analyses. Funct Ecol. 1999;13:289-97.

44. De Meyer J, Irschick DJ, Vanhooydonck B, Losos JB, Adriaens D, Herrel A The role of bite force in the evolution of head shape and head shape dimorphism in Anolis lizards. Funct Ecol. 2019:33:2191-202.

45. Ji X, Zhou WH, He GB, Zhang XD. Sexual dimorphism and reproduction in the grass lizard, Takydromus septentrionalis. Russ J Herpetol. 1998:5:44-8.

46. Hadfield AJ, Ivantsoff V, Johnston PG. Clinal variation in electrophoretic and morphological characters between two nominal species of the genus Pseudomugil (Pisces: Atheriniformes: Pseudomugilidae). Aust J Mar Freshwat Res. 1979;30:375-86.

47. Merrill RM, Rastas P, Martin SH, Melo MC, Barker S, Davey J, McMillan WO, Jiggins CD. Genetic dissection of assortative mating behavior. PLoS Biol. 2019:17:e2005902.

48. Ji X, Tang YW, Hong WX. Further observations on activity pattern and home range the grass lizard, Takydromus septentrionalis during the breeding season. Acta Zool Sin. 1994;40:207-10.

49. Van Doorn GS, Edelaar P, Weissing FJ. On the origin of species by natural and sexual selection. Science. 2009;326:1704-7.

50. Weissing FJ, Edelaar P, Van Doorn GS. Adaptive speciation theory: a conceptual review. Behav Ecol Sociobiol. 2011;65:461-80.

51. Tseng WH, Lin JW, Lou CH, Lee KH, Wu LS, Wang ZY, Wang YY, Irschick DJ, Lin SM. Opsin gene expression regulated by testosterone level in a sexually dimorphic lizard. Sci Rep. 2018;8:16055.

52. Baeckens S, García-Roa R, Martín J, Van Damme R. The role of diet in shaping the chemical signal design of Lacertid lizards. J Chem Ecol. 2017:43:902-10.

53. Baeckens S, Herrel A, Broeckhoven C, Vasilopoulou-Kampitsi M, Huyghe K, Goyens J, Van Damme R. Evolutionary morphology of the lizard chemosensory system. Sci Rep. 2017:7:10141.

54. Bruinjé AC, Coelho FEA, Maggi BS, Costa GC. Chemical signalling behaviour in intrasexual communication of lizards lacking femoral pores. Ethology. 2020;126:772-9.

55. Van Moorleghem C, Van Damme R. The Asian grass lizard (Takydromus sexlineatus) does not respond to the scent of a native mammalian predator. Ethology. 2020;126:509-18

\section{Publisher's Note}

Springer Nature remains neutral with regard to jurisdictional claims in published maps and institutional affiliations. 